\title{
EFEKTIVITAS PENGGUNAAN MEDIA PAPAN WAKTU PADA PEMBELAJARAN PENGHITUNGAN WAKTU BAGI SISWA KELAS III SEKOLAH DASAR
}

\author{
Dyah Rohmawati ${ }^{1}$, Reza Syehma Bahtiar ${ }^{2}$, Tri Dayat ${ }^{3}$ \\ PGSD, Universitas Wijaya Kusuma Surabaya, Indonesia \\ syehma@gmail.com²
}

\begin{abstract}
Abstrak
Salah satu materi matematika yang dianggap siswa sulit adalah penghitungan waktu. Tujuan penelitian ini adalah untuk mengetahui hasil belajar siswa setelah menggunakan media papan waktu dalam pembelajaran penghitungan waktu. Penelitian ini mengunakan metode analisis deskriptif dengan pendekatan kuantitatif. Instrumen yang digunakan dalam penelitian ini adalah tes hasil belajar, observasi, dan angket. Sedangkan analisis data yang digunakan adalah analisis data hasil belajar siswa, analisis data aktifitas guru, analisis data aktifitas siswa, dan analisis data respon siswa.

Berdasarkan hasil penelitian yang telah dilakukan bahwa hasil belajar siswa dikatakan tuntas secara klasikal karena presentase yang diperoleh lebih dari kriteria ketuntasan hasil belajar klasikal yaitu sebesar 83,79 \% dengan jumlah siswa sebanyak 31 siswa yang tuntas belajar dan enam siswa yang tidak tuntas belajar. Observasi aktivitas guru dalam mengelola pembelajaran penghitungan waktu dengan menggunakan media pembelajaran papan waktu dikatakan sangat baik karena hasil yang diperoleh sebesar 92,5. Observasi aktivitas siswa dalam pembelajaran penghitungan waktu dengan menggunakan media pembelajaran papan waktu dikatakan sangat baik karena presentase yang diperoleh sebesar $90 \%$. Sedangkan respon yang diberikan siswa saat menggunakan media pembelajaran papan waktu dikatakan positif karena presentase yang diperoleh sebesar $82,64 \%$. Berdasarkan hasil penelitian yang dilakukan di sekolah dasar tersebut dapat disimpulkan bahwa penggunaan media papan waktu pada pembelajaran penghitungan waktu bagi siswa kelas III Sekolah dasar tahun ajaran 2017-2018 adalah efektif.
\end{abstract}

Kata Kunci: efektivitas, media papan waktu, penghitungan waktu

\section{Abstract}

One of the mathematical material that students find difficult is time calculation. The purpose of this study was to determine student learning outcomes after using time board media in time calculation learning. This research uses descriptive analysis method with a quantitative approach. The instruments used in this study were tests of learning outcomes, observations, and questionnaires. While the data analysis used is the analysis of student learning outcomes data, analysis of teacher activity data, analysis of student activity data, and analysis of student response data.

Based on the results of research that has been done that student learning outcomes are said to be completed in a classical manner because the percentage obtained is more than the classical learning outcomes completeness criteria which is equal to $83.79 \%$ with the number of students as many as 31 students who complete study and six students who do not complete learning. Observation of teacher activities in managing learning in calculating time using board learning media time is said to be very good because the results obtained amounted to 92.5. Observation of student activities in learning to calculate time using board learning media time is said to be very good because the percentage obtained is $90 \%$. While the response given by students when using the time board learning media is said to be positive because the percentage obtained is $82.64 \%$. Based on the results of research conducted in elementary schools it can be concluded that the use of time board media in time calculation learning for grade 3 students of 2017-2018 school year elementary school is effective.

Keywords: effectiveness, time board media, time calculation 


\section{PENDAHULUAN}

Pendidikan merupakan suatu kegiatan untuk mengembangkan potensi yang dimiliki manusia melalui kegiatan pembelajaran. Setiap manusia memiliki hak untuk mendapatkan pendidikan yang layak. Melalui pendidikan seseorang akan memperoleh pengalaman, ilmu, dan pengetahuan yang berguna dalam kelangsungan hidup dalam bermasyarakat. Pendidikan sebagai proses belajar siswa untuk berinteraksi dengan sumber belajar yang memprioritaskan siswa dalam penguasaan kognitif (pengetahuan), psikomotorik (keterampilan), dan afektif (sikap) (Popiyanto \& Yuanta, 2018). Kurikulum 2013 sebagai salah satu dasar pengembangan pendidikan di jenjang sekolah. Kurikulum menjadi pedoman penyelenggaraan kegiatan pembelajaran untuk mencapai tujuan pendidikan bagi satuan pendidikan dan guru (Alawiyah, 2013). Tema pengembangan Kurikulum 2013 adalah agar proses pendidikan dapat menghasilkan insan Indonesia yang produktif, kreatif, inovatif, dan afektif melalui penguatan sikap dan pengetahuan yang terintegrasi (Yasa, 2017).

Matematika adalah mata pelajaran yang penting karena dalam kehidupan sehari-hari, kita tidak boleh mengelak dari aplikasi matematika, matematika juga mampu mengembangkan kesadaran tentang nilai-nilai yang secara esensial (Siagian, 2012). Masih banyak orang yang memandang matematika sebagai bidang studi yang paling sulit, semua orang harus mempelajarinya karena merupakan sarana untuk memecahkan masalah dalam kehidupan sehari-hari, seperti halnya bahasa, membaca, dan menulis. Peran guru untuk menciptakan komunitas matematika di kelas juga sangat strategis, dalam arti bahwa porsi peran guru sebagai pengajar harus proporsional dengan peran lain sebagai fasilitator, partisipan atau bahkan sebagai seorang sahabat di kelas (Umar, 2012). Banyak siswa yang tidak senang dan tidak bersemangat saat pelajaran matematika karena guru kurang memberikan motivasi kepada siswa. Tidak adanya media pembelajaran dalam kegiatan belajar mengajar matematika membuat matematika menjadi pelajaran yang sulit dan membosankan. Kesulitan matematika dapat diatasi sejak dini, jika tidak diatasi akan menghadapi banyak masalah dalam kehidupan sosialnya karena hampir semua mata pelajaran memerlukan matematika. Matematika adalah pengetahuan atau ilmu mengenai logika dan problem-problem numerik. Matematika membahas fakta-fakta dan hubunganhubungan, serta membahas problem ruang dan waktu. Khusus untuk materi bilangan jam (penghitungan waktu) pada tema 6 kurang memuaskan, hal ini disebabkan siswa kurang mampu dalam menghitung penjumlahan dan pengurangan pada materi penghitungan waktu yang dikarenakan pada saat kegiatan pembelajaran guru tidak menggunakan media pembelajaran yang kreatif.

Dalam kegiatan belajar mengajar guru menggunakan media papan tulis dalam mengajarkan materi. Pemahaman materi yang diterima siswa masih bersifat abstrak yang menyebabkan siswa kurang bersemangat dalam pembelajaran serta kurang maksimalnya pemahaman yang diterima siswa. Dalam mata pelajaran matematika yang diajarkan di kelas III SD ini, terdapat materi penghitungan waktu yang menghitung selisih waktu dalam bentuk menit dan detik. Untuk mempermudah materi mengenai penghitungan waktu diperlukan media yang 
menarik dan mudah digunakan siswa tanpa membebani guru dalam pembuatannya. Melalui perkembangan teknologi dan ilmu pengetahuan tersebut para guru dapat menggunakan berbagai media sesuai dengan kebutuhan dan tujuan pembelajaran (Yuanta, 2017). Guru dapat memanfaatkan media elektronik dan non elektronik dalam kegiatan belajar mengajar. Menurut Pratiwi \& Mulyani (2013) banyak alternatif media yang bisa dipakai dalam mendukung kegiatan belajar mengajar di dalam kelas.

Analisis kurikulum diperlukan guru untuk menentukan jenis media yang digunakan dalam pembelajaran. Pemilihan media yang digunakan juga harus sesuai dengan kondisi siswa dan situasi kelas agar dapat digunakan dengan maksimal (Safitri, Fauziyah, \& Nugroho, 2018). Guru juga harus mempertimbangkan kemudahan pengguanaan media dalam kegiatan pembelajaran.

Media pembelajaran adalah alat yang dapat membantu proses belajar mengajar dan berfungsi untuk memperjelas makna pesan yang disampaikan sehingga dapat mencapai tujuan pembelajaran dengan lebih baik dan sempurna (Kustandi \& Bambang, 2011). Media pembelajaran merupakan sarana pendidikan yang dapat digunakan sebagai perantara dalam proses pembelajaran, dengan media pembelajaran siswa mampu mendapatkan pengetahuan, keterampilan, atau sikap untuk tercapainya tujuan pembelajaran.

Dalam penelitian ini media yang digunakan yaitu media papan waktu. Media papan waktu adalah media pembelajaran yang bentuk dan penggunaannya menyerupai jam dinding. Pada jam dinding terdapat mesin jam sedangkan media papan waktu tidak terdapat mesin jam, tetapi sama-sama memiliki jarum jam sebagai penunjuk waktu. Media papan waktu adalah media pembelajaran matematika yang berbentuk lingkaran terbuat dari triplek yang terpasang 2 jarum jam yang terbuat dari stik es krim. Media papan waktu ini dilapisi dengan kain yang berbeda warna dalam setiap angkanya sehingga mempermudah siswa dalam menghitung waktu setiap detik atau menitnya. Media papan waktu digunakan sebagai media pembelajaran matematika yang berkaitan dengan materi penghitungan waktu. Tidak papan waktu memiliki peranan dan manfaat sebagai alat peraga khususnya pada mata pelajaran matematika. Sejalan dengan hasil penelitian Supraptiasih (2013) bahwa penggunaan media jam mampu meningkatkan hasil belajar siswa pada materi waktu. Sehingga hasil penelitian tersebut mendukung penelitian yang dilaksanakan peneliti.

Media papan waktu dapat membantu dalam menjelaskan tentang penghitungan waktu, mengkongkritkan tentang cara menghitung waktu serta diharapkan mampu menciptakan pembelajaran yang aktif dan menyenangkan sesuai tujuan yang ingin dicapai. Perkembangan IPTEK mendorong untuk melakukan upaya pembaharuan dalam pemanfaatan hasil teknologi dalam proses belajar. Hal tersebut menuntut agar guru mampu menggunakan alat-alat yang disediakan oleh sekolah, dan tidak menututup kemungkinan bahwa alat-alat tersebut sesuai dengan perkembangan dan tuntutan zaman. Guru dapat menggunakan media yang dibuat menggunakan alat yang murah, efisien dan sederhana tetapi dapat mencapai tujuan pembelajaran yang diharapkan (Kustandi 
\& Bambang, 2011). Guru juga harus mampu membangkitkan minat belajar siswa melalui sarana pendidikan yang sebagai media pendidikan harus mampu membangkitkan rangsangan indera penglihatan, pendengaran, perabaan, pengecapan, dan penciuman dan untuk tujuan tersebut guru perlu memiliki sebuah media pembelajaran yang memadai, agar bahan ajar dapat diserap siswa dengan sebaik-baiknya (Daryanto, 2015). Oleh karena itu, rumusan masalah dalam penelitian ini adalah apakah media papan waktu pada pembelajaran perhitungan efektif bagi siswa kelas III Sekolah Dasar.

\section{METODE PENELITIAN}

Penelitian ini mengunakan metode analisis deskriptif dengan pendekatan kuantitatif. Penggunaan metode deskriptif kuantitatif diselaraskan dengan variabel penelitian yang memusatkan pada masalah-masalah aktual dan fenomena yang sedang terjadi pada saat sekarang dengan bentuk hasil penelitian berupa angka yang memiliki makna. Tujuan penelitian deskriptif dengan pendekatan kuantitatif ini adalah untuk menjelaskan suatu siuasi yang hendak diteliti dengan dukungan studi kepustakaan sehingga lebih memperkuat analisa peneliti dalam membuat suatu kesimpulan. Penelitian ini dilaksanakan di SDN Petemon XIII/361 Surabaya yang dilaksakan pada tahun ajaran 2017/2018 pada semester genap. Subjek dalam penelitian ini adalah siswa kelas III Sekolah dasar dengan jumlah siswa 37 siswa yang terdiri dari 17 siswa perempuan dan 20 siswa laki-laki.

Instrumen yang digunakan dalam penelitian ini menggunakan observasi, tes hasil belajar, dan angket. Untuk menjawab pertanyaan penelitian, maka data yang diperoleh dianalisis menggunakan analisis deskriptif. Data yang diperoleh meliputi ketuntasan belajar siswa, aktifitas guru dalam penggunaan media, aktifitas siswa dalam pembelajaran, dan respon siswa selama mengikuti pembelajaran.

Data hasil belajar siswa dilihat dari ketuntasan hasil belajar siswa selama mengikuti pembelajaran matematika penghitungan waktu dengan menggunakan media papan waktu yaitu pada nilai akhir dalam tes individu. Siswa akan dinyatakan lulus apabila siswa mendapatkan nilai lebih dari atau sama dengan 75 dari nilai standart sempurna yaitu 100, dan suatu kelas dinyatakan tuntas dalam belajar apabila terdapat lebih dari atau sama dengan $75 \%$ siswa mencapai ketuntasan.

Data tentang kemampuan guru dalam mengelola pembelajaran dengan penggunaan media papan waktu pada pembelajaran matematika materi penghitungan waktu dapat dianalisis dengan menghitung rata-rata setiap aspek kemampuan guru dalam mengelola pembelajaran. Data aktivitas belajar siswa diperoleh dari pengamatan aktivitas siswa selama proses pembelajaran.

\section{HASIL DAN PEMBAHASAN}

Berikut ini akan dibahas tentang data hasil belajar siswa dalam pembelajaran matematika pada materi penghitungan waktu. Data tersebut disajikan dalam Tabel 1. 
Tabel 1 Data Hasil Belajar Siswa dalam Pembelajaran Sekolah Dasar

\begin{tabular}{|c|c|c|c|c|}
\hline No & Nama Siswa & $\begin{array}{c}\text { Jenis } \\
\text { Kelamin }\end{array}$ & Nilai & Keterangan \\
\hline 1 & Abizer & $\mathrm{L}$ & 80 & Tuntas \\
\hline 2 & Adi Firmanzah & $\mathrm{L}$ & 80 & Tuntas \\
\hline 3 & Agung Prawira Wibawa & $\mathrm{L}$ & 70 & Tidak Tuntas \\
\hline 4 & Alya Archelsea Natasya & $\mathrm{P}$ & 50 & Tidak Tuntas \\
\hline 5 & Ayeesha Diva Hayuningtyas & $\mathrm{P}$ & 100 & Tuntas \\
\hline 6 & Bagas Putra Pratama & $\mathrm{L}$ & 100 & Tuntas \\
\hline 7 & Charis Khalista Ardy & $\mathrm{L}$ & 80 & Tuntas \\
\hline 8 & Danang Abdi Pratama & $\mathrm{L}$ & 50 & Tidak Tuntas \\
\hline 9 & Daru Seno Damar Panuluh & $\mathrm{L}$ & 70 & Tidak Tuntas \\
\hline 10 & Dhorifatun Nisa & $\mathrm{P}$ & 100 & Tuntas \\
\hline 11 & Difca August Ratisya & $\mathrm{P}$ & 90 & Tuntas \\
\hline 12 & Einar Sondyanto Wibawa & $\mathrm{L}$ & 100 & Tuntas \\
\hline 13 & Farhan Ubaidillah & $\mathrm{L}$ & 80 & Tuntas \\
\hline 14 & Fiona Nabila Putri & $\mathrm{P}$ & 90 & Tuntas \\
\hline 15 & Hanif Three Septian & $\mathrm{L}$ & 70 & Tidak Tuntas \\
\hline 16 & Hyachinta Azzahra & $\mathrm{P}$ & 90 & Tuntas \\
\hline 17 & Ikiro Dika Gerahana Yume & $\mathrm{L}$ & 90 & Tuntas \\
\hline 18 & Ilyas & $\mathrm{L}$ & 90 & Tuntas \\
\hline 19 & Ivan Agatha Fadhilah & $\mathrm{L}$ & 80 & Tuntas \\
\hline 20 & Keyzaluna Fahira & $\mathrm{P}$ & 80 & Tuntas \\
\hline 21 & Moch. Wildan Ferdiansyah & $\mathrm{L}$ & 90 & Tuntas \\
\hline 22 & Muchammad Musleh & $\mathrm{L}$ & 80 & Tuntas \\
\hline 23 & Muhammad Daffa Alhannan & $\mathrm{L}$ & 100 & Tuntas \\
\hline 24 & Muhammad Rizkyllah & $\mathrm{L}$ & 100 & Tuntas \\
\hline 25 & Muhammad Zein Maulana Akbar & $\mathrm{L}$ & 100 & Tuntas \\
\hline 26 & Nadhira Zahrah Dinatachandra & $\mathrm{P}$ & 100 & Tuntas \\
\hline 27 & Nur Kamalia & $\mathrm{P}$ & 100 & Tuntas \\
\hline 28 & Qurrotul Amaliah & $\mathrm{P}$ & 80 & Tuntas \\
\hline 29 & Revan Ar-Rahman & $\mathrm{L}$ & 100 & Tuntas \\
\hline 30 & Revin Ar-Rahim & $\mathrm{L}$ & 100 & Tuntas \\
\hline 31 & Roudatul Jannah & $\mathrm{P}$ & 100 & Tuntas \\
\hline 32 & Sofy Amalia Putri & $\mathrm{P}$ & 80 & Tuntas \\
\hline 33 & Stillita Afrin Ramadhani & $\mathrm{P}$ & 80 & Tuntas \\
\hline 34 & Syakira Putri Wimas Khairani & $\mathrm{P}$ & 100 & Tuntas \\
\hline 35 & Vera Fadila Tasya & $\mathrm{P}$ & 70 & Tidak Tuntas \\
\hline 36 & Widyastutik Dwi Purdiasari & $\mathrm{P}$ & 80 & Tuntas \\
\hline 37 & Zalfa Indi Salsabila & $\mathrm{P}$ & 80 & Tuntas \\
\hline
\end{tabular}

Berdasarkan penelitian yang dilakukan di kelas III-A SDN Petemon XIII/361 Surabaya, siswa dikatakan tuntas belajar secara individu apabila skor yang diperoleh minimal atau $\geq 75$ sedangkan siswa dianggap tuntas belajar secara klasikal apabila skor yang diperoleh $70 \%$ dari jumlah siswa. Dari data yang disajikan pada tabel 1, terdapat 31 siswa yang tuntas belajar dengan presentase secara klasikal 83,79 \% sedangkan siswa yang tidak tuntas belajar sebanyak 6 siswa dengan presentase secara klasikal 16,21\%. Dengan demikian penelitian dikatakan berhasil apabila mencapai ketuntasan belajar $\geq 75$ sehingga dapat 
dikatakan bahwa efektivitas penggunaan media papan waktu dalam pembelajaran matematika pada materi penghitungan waktu memperoleh presentase tinggi.

Berikut ini akan dibahas tentang data aktivitas guru dalam mengelola pembelajaran matematika pada materi penghitungan waktu. Data tersebut disajikan dalam tabel 2.

Tabel 2 Data Aktivitas Guru dalam Mengelola Pembelajaran Sekolah Dasar

\begin{tabular}{|c|c|c|c|c|c|c|}
\hline \multirow{2}{*}{ No } & \multirow{2}{*}{ Aspek-aspek yang diobservasi } & \multicolumn{4}{|c|}{ Nilai Pengamatan } & \multirow{2}{*}{ Ket. } \\
\hline & & 4 & 3 & 2 & 1 & \\
\hline \multicolumn{7}{|c|}{ Kegiatan Pembukaan Pelajaran } \\
\hline \multicolumn{7}{|c|}{ 1. Tahap Orientasi : } \\
\hline & a. $\quad$ Guru melakukan presensi peserta didik & $\checkmark$ & & & & 4 \\
\hline & $\begin{array}{l}\text { b. Guru menjelaskan kepada siswa tentang } \\
\text { pembelajaran matematika penghitungan waktu } \\
\text { yang akan di terapkan dan menyampaikan } \\
\text { tujuan pembelajaran }\end{array}$ & & $\checkmark$ & & & 3 \\
\hline & c. Apersepsi : Guru memotivasi siswa & $\checkmark$ & & & & 4 \\
\hline \multicolumn{7}{|c|}{ Kegiatan Inti Pelajaran } \\
\hline \multirow[t]{6}{*}{2.} & Tahap Inti : & & & & & \\
\hline & $\begin{array}{l}\text { a. Guru menjelaskan materi kepada siswa serta } \\
\text { memberikan contoh dan stimulus }\end{array}$ & $\checkmark$ & & & & 4 \\
\hline & b. Membentuk kelompok untuk berdiskusi & & $\checkmark$ & & & 3 \\
\hline & c. Guru membimbing kelompok belajar & $\checkmark$ & & & & 4 \\
\hline & d. Guru mengatur jalannya diskusi & $\checkmark$ & & & & 4 \\
\hline & e. Guru memberikan tugas kepada siswa & $\checkmark$ & & & & 4 \\
\hline \multicolumn{7}{|c|}{ Kegiatan Penutup Pelajaran } \\
\hline \multirow[t]{3}{*}{3.} & Tahap Kulminasi : & & & & & \\
\hline & $\begin{array}{l}\text { a. Guru mengadakan beberapa pertanyaan yang } \\
\text { berkaitan dengan materi yang disampaikan } \\
\text { serta menyimpulkan hasil dari pembelajaran }\end{array}$ & & $\checkmark$ & & & 3 \\
\hline & $\begin{array}{l}\text { b. Guru bersama siswa mengakhiri pelajaran } \\
\text { dengan berdoa }\end{array}$ & $\checkmark$ & & & & 4 \\
\hline
\end{tabular}

Pada tabel 2 menunjukkan bahwa nilai rata-rata yang diperoleh dari aktivitas guru kelas III-A SDN Petemon XIII/361 Surabaya dalam mengelola pembelajaran adalah 92,5. Jika dibuat interpretasi untuk setiap aspek, maka dapat disimpulkan bahwa guru sangat baik dalam menjelaskan materi, mengelola kelas, memotivasi siswa dan komunikasi dengan siswa.

Data aktivitas siswa dalam pembelajaran matematika pada materi penghitungan waktu dapat dilihat pada tabel 3 .

Tabel 3 Data Aktivitas Siswa dalam Pembelajaran Sekolah Dasar

\begin{tabular}{clcc}
\hline No & \multicolumn{1}{c}{ Aspek Perhatian } & $\begin{array}{c}\text { Jumlah } \\
\text { Siswa }\end{array}$ & $\begin{array}{c}\text { Presentase } \\
(\%)\end{array}$ \\
\hline 1. & Memperhatikan penjelasan / mendengarkan guru & 35 & $94,5 \%$ \\
\hline 2. & $\begin{array}{l}\text { Tidak mengganggu teman / Tidak berbicara ketika guru } \\
\text { menjelaskan }\end{array}$ & 35 & $94,5 \%$ \\
\hline 3. & Fokus pada diskusi kelompok & 34 & $91,8 \%$ \\
\hline \multicolumn{2}{c}{ Presentase Nilai Rata-Rata } & & $93,6 \%$ \\
\hline
\end{tabular}




\begin{tabular}{|c|c|c|c|}
\hline No & Aspek Keaktifan & $\begin{array}{l}\text { Jumlah } \\
\text { Siswa }\end{array}$ & $\begin{array}{l}\text { Presentase } \\
(\%)\end{array}$ \\
\hline 1. & Melakukan pengamatan atau penyelidikan teks & 34 & $91,8 \%$ \\
\hline 2. & $\begin{array}{l}\text { Membaca dengan aktif (misal dengan pensil/bulpoin di } \\
\text { tangan untuk menggaris bawahi atau membuat catatan } \\
\text { kecil atau tanda-tanda tertentu pada buku) }\end{array}$ & 37 & $100 \%$ \\
\hline \multirow[t]{2}{*}{3.} & $\begin{array}{l}\text { Mendengarkan dengan aktif (menunjukkan respon, } \\
\text { misal tersenyum atau tertawa saat mendengar hal-hal } \\
\text { lucu yang disampaikan, terkagum-kagum bila } \\
\text { mendengar sesuatu yang menakjubkan, dsb) }\end{array}$ & 36 & $97,2 \%$ \\
\hline & Presentase Nilai Rata-Rata & & $96,33 \%$ \\
\hline No & Aspek Partisipasi & $\begin{array}{c}\text { Jumlah } \\
\text { Siswa }\end{array}$ & $\begin{array}{c}\text { Presentase } \\
(\%)\end{array}$ \\
\hline 1. & $\begin{array}{l}\text { Berlatih (misalnya mencobakan sendiri konsep-konsep } \\
\text { misal berlatih dengan soal-soal) }\end{array}$ & 35 & $94,5 \%$ \\
\hline 2. & Mampu menjelaskan dan mengemukakan pendapat & 30 & $81 \%$ \\
\hline 3. & Berdiskusi & 30 & $81 \%$ \\
\hline \multicolumn{2}{|r|}{ Presentase Nilai Rata-Rata } & & $85,5 \%$ \\
\hline No & Aspek Pemahaman & $\begin{array}{l}\text { Jumlah } \\
\text { Siswa }\end{array}$ & $\begin{array}{l}\text { Presentase } \\
(\%)\end{array}$ \\
\hline 1. & Mengomentari dan menyimpulkan proses pembelajaran & 32 & $86,4 \%$ \\
\hline 2. & $\begin{array}{l}\text { Memperbaiki kesalahan atau kekurangan dalam proses } \\
\text { pembelajaran }\end{array}$ & 32 & $86,4 \%$ \\
\hline 3. & \multirow{2}{*}{$\begin{array}{ll}\text { Menyimpulkan } & \text { materi pembelajaran der } \\
\text { katanya sendiri } & \\
& \text { Presentase Nilai Rata-Rata }\end{array}$} & 30 & $81 \%$ \\
\hline & & & $84,6 \%$ \\
\hline
\end{tabular}

Dalam pengamatan aktivitas siswa dalam pembelajaran, peneliti membawa absensi dan pedoman pengamatan. Peneliti akan mengamati aktivitas sesuai dengan pedoman pengamatan dengan mencatat jumlah siswa yang disesuaikan dengan setiap aktivitas yang terdapat pada pedoman pengamatan.

Berikut ini akan dibahas tentang data angket respon siswa dalam pembelajaran matematika pada materi penghitungan waktu. Data tersebut disajikan dalam tabel 4.

Tabel 4 Rekapitulasi Angket Respon Siswa Sekolah dasar

\begin{tabular}{cccccccc}
\hline \multirow{2}{*}{ Pernyataan No } & \multicolumn{9}{c}{ Pilihan Jawaban } & \multirow{2}{*}{ R) } & \multirow{2}{*}{ Skor } \\
\cline { 2 - 7 } & SS & S & T & TS & STS & & \\
\hline 1 & 21 & 8 & 3 & 3 & 2 & 37 & 154 \\
\hline 2 & 31 & 6 & 0 & 0 & 0 & 37 & 179 \\
\hline 3 & 15 & 12 & 5 & 2 & 3 & 37 & 145 \\
\hline 4 & 26 & 10 & 1 & 0 & 0 & 37 & 173 \\
\hline 5 & 23 & 9 & 4 & 1 & 0 & 37 & 165 \\
\hline 6 & 4 & 6 & 4 & 10 & 13 & 37 & 133 \\
\hline 7 & 4 & 1 & 4 & 13 & 15 & 37 & 145 \\
\hline 8 & 2 & 5 & 1 & 12 & 17 & 37 & 148 \\
\hline 9 & 2 & 2 & 4 & 10 & 19 & 37 & 153 \\
\hline 10 & 5 & 5 & 4 & 8 & 15 & 37 & 134 \\
\hline
\end{tabular}


Pada data angket respon siswa terdapat 10 pernyataan, yaitu 5 pernyataan positif dan 5 pernyataan negatif. Hasil dari angket respon siswa menunjukkan bahwa pernyataan positif yang pertama yaitu pembelajaran dengan menggunakan media papan waktu lebih menyenangkan dibanding hanya dengan metode ceramah saja, ada 37 siswa yang memilih kategori SS sebanyak 21 siswa, S sebanyak 8 siswa, TT sebanyak 3 siswa, TS sebanyak 3 siswa, STS sebanyak 2 siswa.

Pernyataan positif yang kedua yaitu cara belajar seperti ini menjadikan saya senang belajar dalam hal ini dari 37 siswa yang memilih kategori SS sebanyak 31 siswa, S sebanyak 6 siswa, TT sebanyak 0 siswa, TS sebanyak 0 siswa, STS sebanyak 0 siswa.

Pernyataan positif yang ketiga yaitu saya lebih suka belajar kelompok daripada belajar sendiri-sendiri dalam hal ini dari 37 siswa yang memilih kategori SS sebanyak 15 siswa, S sebanyak 12 siswa, TT sebanyak 5 siswa, TS sebanyak 2 siswa, STS sebanyak 3 siswa. Pernyataan positif yang keempat yaitu dengan cara belajar seperti ini, membuat saya lebih menghargai pendapat orang lain dalam hal ini dari 37 siswa yang memilih kategori SS sebanyak 26 siswa, S sebanyak 10 siswa, TT sebanyak 1 siswa, TS sebanyak 0 siswa, STS sebanyak 0 siswa. Pernyataan positif yang kelima yaitu cara belajar yang baru saja berlangsung sangat menarik dalam hal ini dari 37 siswa yang memilih kategori SS sebanyak 23 siswa, S sebanyak 9 siswa, TT sebanyak 4 siswa, TS sebanyak 1 siswa, STS sebanyak 0 siswa.

Pernyataan negatif yang pertama yaitu saya kurang bisa menangkap dengan jelas materi yang disampaikan dalam hal ini dari 37 siswa yang memilih kategori SS sebanyak 4 siswa, S sebanyak 6 siswa, TT sebanyak 4 siswa, TS sebanyak 10 siswa, STS sebanyak 13 siswa. Pernyataan negatif yang kedua yaitu pembelajaran ini kurang menarik bagi saya dalam hal ini dari 37 siswa yang memilih kategori SS sebanyak 4 siswa, S sebanyak 1 siswa, TT sebanyak 4 siswa, TS sebanyak 13 siswa, STS sebanyak 15 siswa. Pernyataan negatif yang ketiga pembelajaran menggunakan media papan waktu membuat saya cepat bosan yaitu dalam hal ini dari 37 siswa yang memilih kategori SS sebanyak 2 siswa, S sebanyak 5 siswa, TT sebanyak 1 siswa, TS sebanyak 12 siswa, STS sebanyak 17 siswa. Pernyataan negatif yang keempat yaitu cara belajar seperti ini membuat saya lebih senang mengobrol dengan teman daripada mendengarkan guru dalam hal ini dari 37 siswa yang memilih kategori SS sebanyak 2 siswa, S sebanyak 2 siswa, TT sebanyak 4 siswa, TS sebanyak 10 siswa, STS sebanyak 19 siswa. Pernyataan negatif yang kelima yaitu saya setuju kalau media papan waktu tidak cocok untuk pembelajaran ini dalam hal ini dari 37 siswa yang memilih kategori SS sebanyak 5 siswa, S sebanyak 5 siswa, TT sebanyak 4 siswa, TS sebanyak 8 siswa, STS sebanyak 15 siswa.

Berdasarkan hasil analisa data diatas menunjukkan bahwa (1) hasil belajar siswa mencapai ketuntasan klasikal sebesar 83,79 \% (ketuntasan terpenuhi); (2) hasil observasi aktivitas guru dalam mengelola pembelajaran sebesar 92,5 (kategori baik terpenuhi); (3) hasil observasi aktivitas siswa dalam pembelajaran 
sebesar $90 \%$ (kategori aktif terpenuhi); dan (4) hasil angket respon siswa sebesar $82,64 \%$ (kategori positif terpenuhi).

Berdasarkan empat unsur yang telah dilakukan analisis dengan hasil terpenuhi, maka penggunaan media papan waktu pada pembelajaran penghitungan waktu bagi siswa kelas III SDN Petemon XIII/361 Surabaya tahun ajaran 20172018 adalah efektif. Hal ini sejalan dengan penelitian (Sehat, 2013) yang menyatakan bahwa media jam dinding dapat meningkatkan hasil belajar siswa kelas $\mathrm{V}$ dalam pembelajaran matematika pokok bahasan pengukuran waktu.

\section{KESIMPULAN DAN SARAN}

Berdasarkan penelitian yang dilakukan di kelas III-A Sekolah dasar dapat disimpulkan bahwa penggunaan media papan waktu pada pembelajaran penghitungan waktu bagi siswa kelas III Sekolah dasar tahun ajaran 2017-2018 adalah efektif. Sedangkan berdasarkan kesimpulan penelitian efektivitas penggunaan media papan waktu pada pembelajaran penghitungan waktu bagi siswa kelas III-A di Sekolah dasar, maka peneliti menyampaikan saran sebagai berikut : (1) bagi kepala sekolah, hendaknya membimbing dan mengarahkan guru dalam penggunaan media pembelajaran yang inovatif pada pembelajaran di kelas agar dapat meningkatkan hasil belajar siswa; (2) bagi guru, hendaknya dapat mengembangkan penggunaan media papan waktu sebagai sumber belajar; (3) bagi peneliti selanjutnya, penelitian ini dapat digunakan sebagai bahan referensi dalam penelitian penggunaan media pembelajaran atau penggunaan media papan waktu.

\section{DAFTAR RUJUKAN}

Alawiyah, F. (2013). Peran Guru dalam Kurikulum 2013. Aspirasi, 4(1), 65-74. Retrieved from http://jurnal.dpr.go.id/index.php/aspirasi/article/view/480

Daryanto. (2015). Media Pembelajaran. Bandung: PT Sarana Tutorial Nurani Sejahtera.

Kustandi, C., \& Bambang, S. (2011). Media Pembelajaran Manual dan Digital. Bogor: Ghalia Indonesia.

Popiyanto, Y., \& Yuanta, F. (2018). Pengaruh Web Centric Course Berbasis Information Technology Terhadap Pengaruh Web Centric Course Berbasis Information Technology Terhadap Hasil Belajar Siswa Sekolah Dasar. Inovasi, $x x(2), 25-31$. Retrieved from https://fbs.uwks.ac.id

Pratiwi, D. E., \& Mulyani. (2013). Penerapan Media Papan Balik ( Flipchart ) Pada Pembelajaran Tematik. JPGSD, 1(2).

Safitri, S. R., Fauziyah, N., \& Nugroho, A. S. (2018). Peningkatan Kemampuan Menulis Deskripsi melalui Media Kartu Kata Bergambar pada Siswa Kelas 1 Sekolah Dasar. JTIEE, 2(2), 85-93. https://doi.org/http://dx.doi.org/10.30587/jtiee.v2i2.758

Sehat, D. (2013). Peningkatan hasil belajar pada pembelajaran materi pengukuran waktu dengan pemanfaatan media jam. JIPP, 2(7). Retrieved from http://jurnal.untan.ac.id/index.php/jpdpb/article/view/2707

Siagian, R. E. F. (2012). Pengaruh Minat dan Kebiasaan Belajar Siswa Terhadap Prestasi Belajar Matematika. Jurnal Formatif, Vol 2(2), 122-131. 
https://doi.org/http://journal.lppmunindra.ac.id/index.php/Formatif/article/vie wFile/750/659

Supraptiasih. (2013). Penggunaan media jam pembelajaran matematika materi waktu kelas I SDN 01 Sungai Raya Kepulauan. JIPP, 2(3). Retrieved from http://jurnal.untan.ac.id/index.php/jpdpb/article/view/1459

Umar, W. (2012). Membangun Kemampuan Komunikasi Matematis dalam Pembelajaran Matematika. Jurnal Infinity, 1(1), 1-9. https://doi.org/10.22460/infinity.v1i1.2

Yasa, A. D. (2017). Penguasaan Konsep dan Keterampilan Pemecahan Masalah setelah Diajarkan dengan Pendekatan Keterampilan Proses, 1(1), 69-80. Retrieved from http://ejournal.unikama.ac.id/index.php/JBPD

Yuanta, F. (2017). Pengembangan Media Audio Visual Mata Pelajaran Bahasa Indonesia Untuk Sekolah Dasar. Ibriez, 2(2), 59-69. https://doi.org/https://doi.org/10.21154/ibriez.v2i2.36 